\title{
REPENSANDO O PROCESSO DE EMPRESARIZAÇÃO: A INSERÇÃO DE UM OLHAR DE INSPIRAÇÃO FOUCAULTIANA
}

\author{
Alice Hubner Franz ${ }^{1}$ \\ Marcio Silva Rodrigues ${ }^{2}$
}

\begin{abstract}
Resumo
As sociedades modernas têm vivenciado um processo caracterizado por uma ampla e forte influência do modelo empresarial sobre os humanos, suas organizações e instituições, conhecido como processo de empresarização do mundo. Dito isso, o ponto central deste artigo é explorar o processo de empresarização do mundo a partir da realização de uma discussão que aborda os estudos já realizados sobre este tema no âmbito brasileiro dos estudos organizacionais. Intenta-se propor um novo caminho para se repensar os escritos sobre esse fenômeno à luz de uma perspectiva foucaultiana. A partir desse novo olhar, com base na obra de Michel Foucault, busca-se apontar aos estudos sobre o processo de empresarização novas contribuições teóricas, metodológicas e epistemológicas, as quais podem vir a auxiliar na compreensão e no aprofundamento deste fenômeno, destacando a operacionalidade e potencialidade da leitura foucaultiana às pesquisas que englobam esse tema.
\end{abstract}

Palavras-chave: Empresarização. Empresa. Michel Foucault.

1 Graduada em Administração e Mestra e Desenvolvimento Territorial e Sistemas Agroindustriais da Universidade Federal de Pelotas (UFPel).E-mail: alicefranz1@gmail.com

2 Doutor em Administração pela Universidade Federal de Santa Catarina (UFSC). Professor Adjunto do Departamento de Administração da Universidade Federal de Pelotas (UFPel). E-mail: marciosilvarodrigues@gmail.com 


\section{Introdução}

No contexto de emergência da modernidade-e,mais especificamente, com a consolidação do modo de produção capitalista -, tem-se início um processo, até então inédito, protagonizado pela dominação da empresa sobre todos os aspectos do social. Diante disso, as sociedades modernas passaram por uma série de transformações, as quais acabaram por consolidar novas relações sociais, novas formas de estar no mundo, novos conhecimentos e novas crenças, os quais, no limite, acabaram por contribuir para colocar a empresa como uma organização central do nosso tempo (DARDOT; LAVAL, 2016). É possível citar, ao menos, três manifestações comuns da centralidade da empresa em nosso mundo, tais como a rápida expansão geográfica da empresa, a sua crescente influência exercida sobre os humanos dentro e fora de seu contexto e o aumento progressivo de seu domínio sobre outras organizações e atividades humanas (SOLÉ, 2008).

Entende-se que essa centralidade assumida pela empresa na modernidade passou a desencadear um processo que Solé $(2004,2008)$ denomina de empresarização do mundo, ou seja, um processo que reflete a crescente influência que a ideia de empresa passa a exercer sobre os humanos modernos e sobre suas organizações e instituições, configurandose, de acordo com esse autor, na nova força organizadora das sociedades contemporâneas (SOLÉ, 2004, 2008). Uma instituição central que, segundo Abraham (2006), é sustentada por um conjunto de maneiras de agir e de pensar típicas da modernidade (o individualismo e a invenção da realidade econômica; o mito fundador da escassez; a propriedade privada, a apropriação e a exploração; o racionalismo, a racionalidade e a burocracia; a inovação, o desenvolvimento e a ideologia do progresso).

Como consequência desse processo, tanto a linguagem utilizada nas empresas, como as suas técnicas, os seus métodos, as suas ferramentas e as suas práticas não mais se restringem apenas às suas fronteiras, exteriorizando-se para outros domínios do social. À vista disso, não é raro encontrar organizações e instituições que, originalmente, não possuem um caráter empresarial, estão incorporando os pressupostos mencionados (SOLÉ, 2008).

Conforme apontam Rodrigues e Silva (2019a), o debate acerca da ideia de empresarização ou ainda, de empresariamento - como é por vezes empregada - já vem sendo feito por alguns autores em seus escritos nas mais diferentes áreas do conhecimento, tal como na educação através dos estudos organizados por Neves (2002), no âmbito da geografia e do urbanismo com Vainer (2000) e Harvey (2007) e, ainda, em estudos voltados às políticas públicas por meio das reflexões de Considine (2001).

Frente a isso, percebe-se que o processo de empresarização é um fenômeno estudado em diversos campos do conhecimento. Entretanto, 
especificamente na área dos estudos organizacionais, as pesquisas sobre este tema têm utilizado como referência a perspectiva teórica de dois autores, a saber: Andreu Solé (2004, 2008) e Yves Abraham (2006). No Brasil, as pesquisas utilizando o cabedal teórico de ambos os autores começaram no início dos anos 2000 e estão sendo desenvolvidas até os dias de hoje por um grupo, ainda restrito, de pesquisadores dentro da área dos estudos organizacionais.

Tendo em vista o breve panorama que foi exposto, destaca-se que o esforço empreendido no presente trabalho está direcionado à articulação e disseminação de um aparato teórico que permita compreender, de forma complementar ao que já foi escrito, o fenômeno da empresarização. Assim, neste ensaio teórico, discutir a ideia de empresa e o processo de empresarização, a partir da realização de um levantamento das pesquisas desenvolvidas sobre a temática dentro dos estudos organizacionais brasileiros e da articulação de um novo olhar para o fenômeno por meio de uma perspectiva foucaultiana.

O norte teórico que se pretende desenvolver aqui com relação à ideia de empresa e de empresarização parte dos estudos de Solé $(2004,2008)$ e de Abraham (2006), e procura avançar teoricamente com a inserção de um olhar de inspiração Foucaultiana. Para tanto, optou-se pela elaboração de um artigo de cunho teórico, realizado a partir de uma revisão dos escritos acerca da teoria da empresarização nos estudos organizacionais, bem como dos escritos do filósofo Michel Foucault. A partir da revisão teórica de ambos os aportes, buscou-se desenvolver e traçar algumas contribuições para a teoria da empresarização que pudessem suprir algumas lacunas existentes no que fora até então desenvolvido, além de apresentar um novo olhar, um novo caminho para se pensar o processo de empresarização nos estudos organizacionais.

É importante frisar que neste trabalho se adota uma postura crítica com relação a essa ampla disseminação da empresa como ideia ou modelo, a qual parece produzir consequências não apenas em organizações com naturezas distintas, mas em toda a sociedade. Acredita-se que, ao naturalizar e tomar a empresa como modelo ideal, inclusive para organizar a própria vida dos indivíduos, acaba-se desprezando uma série de fatores históricos e contextuais inerentes à constituição de cada organização e, mais ainda, limita-se o surgimento de novas e diferentes possibilidades de pensar a realidade, em especial, a realidade organizacional.

Feitas essas considerações introdutórias, na segunda parte deste artigo busca-se contextualizar a teoria da empresarização segundo a visão de Solé (2004, 2008) e de Abraham (2006), bem como elaborar um levantamento dos trabalhos já realizados sobre o tema no Brasil, para, em seguida, em um terceiro momento, apontar outro caminho para esta perspectiva 
3 Para uma visão mais aprofundada acerca das perspectivas apresentadas por Solé e Abraham, ver: Rodrigues e Silva (2019a). em construção a partir da inserção de um olhar Foucaultiano. Para finalizar, na quarta e última seção deste trabalho, apresentam-se algumas considerações finais sobre o que fora até então discutido.

\section{Estudos organizacionais e o processo de empresarização: um breve panorâma das pesquisas brasileiras}

A presente seção visa a realizar uma abordagem acerca da teoria da empresarização, priorizando uma discussão que engloba os seus diferentes usos através de uma exploração centrada na produção científica acumulada sobre o tema no âmbito brasileiro dos estudos organizacionais. Antes de iniciar a construção de um panorama destas pesquisas, torna-se importante contextualizar o que os dois autores, Andreu Solé $(2004,2008)$ e Yves Abraham (2006), utilizados como ponto de partida para se pensar o processo de empresarização neste trabalho, compreendem por "empresa”, isto é, qual o modelo teórico de empresa desenvolvido e defendido por ambos.

Na visão de Solé (2004, 2008), a empresa é uma organização moderna, de características singulares, cujo modelo organizativo tem sido, cada vez mais, tomado como referência para outras organizações. Para o autor, dada essa ampla disseminação do modelo empresarial para outras esferas que não possuem as mesmas características da empresa, esta se tornou a força organizadora do mundo moderno, o qual ele denomina de mundo-empresa. É a partir desse argumento central que advém o conceito de empresarização do mundo, caracterizado pela ampla influência do modelo empresarial no mundo.

Tomando como ponto de partida o trabalho de Solé, em "Lentreprise est-elle nécessaire?” o autor Yves Abraham (2006), inspirado em Émile Durkheim, entende que é preciso aprofundar a compreensão acerca das maneiras de agir e de pensar que dão sustentação à empresa. Dessa forma, o autor compreende a empresa como uma instituição típica da modernidade sustentada pelo individualismo e pela invenção da realidade econômica, pelo mito fundador da escassez, pela noção de propriedade privada, apropriação e exploração, pelo racionalismo, racionalidade e burocracia e pela inovação, desenvolvimento e ideologia do progresso ${ }^{3}$.

Os pressupostos teóricos de ambos os autores têm sido utilizados como referência para se pensar o processo de empresarização em pesquisas brasileiras nas mais diferentes organizações modernas. Em geral, o grupo de pesquisadores que tem se dedicado à análise do processo de empresarização vem realizando um esforço para adaptar as teorias dos autores para o contexto brasileiro, já que elas advêm de um olhar eurocentrado. Também existe um esforço, por parte dos pesquisadores, para operacionalizar os escritos, essencialmente teóricos, de ambos os autores. Desse modo, as pesquisas que são desenvolvidas, de certo modo, colocam essas teorias em perspectiva 
a partir da verificação prática do funcionamento do fenômeno no Brasil. Com a evolução desses estudos, outras leituras foram incorporadas às abordagens de Solé e de Abraham com o intuito de aprofundar e contribuir com algumas discussões que os autores trabalharam de forma superficial.

Em uma tentativa de construção de um panorama dos trabalhos realizados no Brasil até o presente momento, os quais articulam o processo de empresarização e os estudos organizacionais, optou-se por dividi-los em três distintos momentos ou fases de desenvolvimento.

Os primeiros estudos realizados sobre o tema no Brasil, iniciados nos anos 2000, assentaram-se, essencialmente, nos escritos de Solé e focavamse, sobretudo, na análise de como o processo de empresarização estava adentrando determinadas organizações religiosas, esportivas e culturais e, por sua vez, modificando a estrutura organizacional e os seus processos de controle. Dentro desse primeiro grande grupo de estudos desenvolvidos, citam-se os trabalhos de Serra (2005) e Gonçalves, Serra e Costa (2007), os quais se empenharam em analisar o que esses autores denominaram de "empresarização do sagrado", a partir de uma discussão que buscou verificar a existência de uma vinculação entre o processo de empresarização e as mudanças na estrutura organizacional de igrejas evangélicas brasileiras.

As organizações esportivas também foram objeto de análise de pesquisadores, os quais optaram por utilizar como referência teórica os escritos de Solé. Os trabalhos de Costa (2005) e Costa e Silva (20065) orientaram-se à análise de diferentes clubes de futebol catarinenses e à relação entre o processo de empresarização e a sua influência no que tange ao controle organizacional desses clubes. $O$ futebol também esteve presente nas discussões propostas por Rodrigues (2006), Rodrigues e Silva (2006a), Rodrigues e Silva (2006b) e Rodrigues e Silva (2009), a partir de estudos que englobam o processo de empresarização de clubes de futebol brasileiros e a existência de modificações na configuração de sua estrutura organizacional. De outro modo, Durieux (2005) deteve-se na análise de clubes de voleibol brasileiros; e, seguindo uma linha semelhante dos demais trabalhos, o autor buscou identificar a influência do processo de empresarização no arranjo organizacional dos mesmos.

Dentro desse primeiro grande grupo, destacam-se outros dois estudos voltados para a análise do impacto do processo de empresarização em diferentes organizações culturais, tal como proposto por Tavares (2011), ao analisar um grupo circense gaúcho, e por Vargas (2018), ao desenvolver um estudo de caráter quantitativo em Centros de Tradições Gaúchas. Já o trabalho desenvolvido por Rodrigues, Silva e Dellagnelo (2014) sintetiza os estudos sobre organizações esportivas e culturais, a partir da análise de quatro diferentes dimensões do processo de empresarização, quais sejam: orientação mercadológica, aspectos legais, linguagem e organização do trabalho. 
Em síntese, nesse primeiro conjunto de estudos realizados, o qual se deteve aos escritos de Solé $(2004,2008)$ como referencial para discutir o processo de empresarização, as análises estavam mais voltadas à identificação da existência do processo de empresarização e à intensidade do seu desenvolvimento em determinadas instituições (culturais, esportivas e religiosas), bem como a inter-relação entre esse processo e seus impactos na configuração da estrutura e dos processos organizacionais dessas organizações.

Posteriormente, ao notar a falta de um aprofundamento teórico referente aos escritos de Solé $(2004,2008)$, os estudos acerca do processo de empresarização passaram a englobar o cabedal teórico de Abraham (2006) e a explorar os hábitos coletivos (maneiras de agir e de pensar) que sustentam a ideia de empresa na modernidade, os quais contribuem para que esta se torne a instituição referência deste mundo.

Pode-se afirmar que as pesquisas acerca do processo de empresarização adentraram em uma segunda fase de desenvolvimento, na qual as análises foram estendidas para outros âmbitos a partir do estudo de organizações distintas daquelas analisadas no primeiro momento. Araújo (2014) e Araújo e Silva (2016), por exemplo, empenharam-se na análise das políticas públicas voltadas para a agricultura familiar e a expansão das relações sociais típicas empresariais para esse universo. Já Rodrigues (2013) voltou os seus olhares para a mídia, buscando compreender como esta, por meio da produção e da disseminação de seu discurso sobre a educação superior, acaba por colaborar com a construção e a manutenção da empresa enquanto uma instituição típica da modernidade. A educação também foi objeto de análise no estudo proposto por Badia (2017), por meio qual o autor buscou compreender o papel de grupos empresariais privados na elaboração do Plano Nacional de Educação (PNE 2014-2024) e a sua relação com as maneiras de agir e de pensar típicas empresariais.

Além da ampliação do debate acerca do processo de empresarização para outras organizações, neste segundo grupo de estudos, os quais passaram a englobar as reflexões de Abraham (2006), as discussões centraram-se na identificação da presença e do fortalecimento dos diferentes modos de agir e de pensar inerentes às empresas em organizações cujas características e finalidades distinguem-se daquelas presentes no mundo empresarial. Os estudos também demonstraram uma preocupação com a evolução do debate, a qual inclui compreender as possíveis implicações da ampla disseminação desses traços e de como eles contribuem para manter a centralidade da empresa no mundo moderno.

Em um terceiro momento, os estudos sobre o processo de empresarização avançaram a partir da inclusão de outros autores visando, sobretudo, ao enriquecimento das discussões sobre o tema e à 
sua complementariedade a partir da abordagem de questões ainda não trabalhadas nas pesquisas anteriores. Nesse novo conjunto de estudos, pode-se citar o trabalho de Costa (2017), cujo objetivo é compreender como o processo de empresarização se manifesta na (re)organização do espaço de uma cidade brasileira localizada no Rio Grande do Sul. Para tanto, além de Solé e Abraham, a autora utilizou, em suas discussões, os escritos de Florestan Fernandes e a sua abordagem sobre o desenvolvimento do capitalismo dependente, bem como utilizou as contribuições de Milton Santos para pensar e discutir a noção de espaço. Ao associar Florestan Fernandes e Milton Santos, a autora intentou, de certa forma, apropriar os conhecimentos teóricos acerca da empresarização ao contexto brasileiro.

Já Borges e Rodrigues (2017), buscaram compreender como a atuação do Estado contribui com o processo de empresarização do campo da cultura em uma cidade gaúcha. Para tanto, articularam à teoria da empresarização uma perspectiva foucaultiana, a qual “[...] chama a atenção para a importância do Estado e para a maneira como agentes públicos, por estarem assim como todos nós, sujeitos a este poder, tendem a incorporar e reproduzir a ideia de empresa" (BORGES; RODRIGUES, 2017, p. 83).

O Estado também foi central na discussão proposta por Duquia (2018) ao analisar, à luz da teoria da empresarização, os processos de organização da pós-graduação brasileira, a partir de um estudo realizado em uma universidade localizada no Rio Grande do Sul. Visando a complementar a abordagem acerca do processo de empresarização e estender, sobretudo, as possibilidades analíticas do estudo, a autora articulou as contribuições de Mark Considine, posto que o autor possui um arcabouço teórico que trabalha determinados aspectos relacionados à ação e às formas de organização do Estado com mais profundidade.

Para analisar o impacto do processo de empresarização sobre a administração pública, Borges, Barcelos e Rodrigues (2018), lançaram seus olhares para a área da saúde pública brasileira, mais especificamente para a construção e para a implantação da Empresa Brasileira de Serviços Hospitalares (EBSERH), articulando, para tanto, além dos trabalhos de Solé (2004, 2008) e Abraham (2006), autores institucionais. Em outro estudo, Barcelos e Rodrigues (2017) buscaram associar a discussão acerca da empresarização junto a autores do âmbito das políticas públicas para analisar as concepções de políticas públicas e as práticas discursivas voltadas à educação superior durante o período de 2003 a 2010.

Resgatando um texto escrito em 2003 por Solé, também é importante mencionar os trabalhos de Tometich (2019) e Tometich e Silva (2018), as quais - a partir uma pesquisa que associa a teoria da empresarização e os escritos Karl Marx - propõem uma revisão do "assalariamento" como uma característica típica e fundamental do mundo-empresa, apontando para a 
4 No que tange a essa tripartite cronológica da obra de Michel Foucault, Gomes (2012, p. 37) esclarece que ao "[...] primeiro período, a chamada fase arqueológica de necessidade da sua substituição pelo termo "exploração do trabalho". Um dos propósitos das autoras ao utilizar Karl Marx é tentar reduzir a tensão existente, nos escritos de Solé, entre abordagens idealistas e abordagens materialistas para se pensar a noção de empresa.

Em um esforço de síntese deste terceiro momento dos estudos sobre empresarização, percebe-se uma maior preocupação, por parte dos autores, em questionar e compreender como determinadas organizações, sobretudo o Estado nas suas diferentes áreas de atuação, passaram a incorporar e a disseminar os pressupostos empresariais nos seus modos de organizar. Observa-se, também, uma busca pelo preenchimento de lacunas teóricas apontadas em estudos anteriores, além de uma preocupação com relação à inserção de novos olhares que possam contribuir para o avanço da teoria da empresarização.

Considerando todos os aspectos até então mencionados sobre a ideia de empresa e sobre o processo de empresarização, além de todos os estudos até aqui desenvolvidos ilustrados anteriormente, busca-se, neste artigo, avançar na articulação e na explicação do que foi proposto a partir da inserção e do desenvolvimento de um olhar de inspiração foucaultiana para se pensar o processo de empresarização, visando, sobretudo, a eliminar algumas lacunas da produção teórica dos autores, além de lançar uma nova contribuição para os estudos dessa área.

A necessidade de compreender a empresa e, consequentemente, o processo de empresarização a partir de uma perspectiva foucaultiana já foi mencionada em um artigo publicado em 2019, na revista Farol, por Rodrigues e Silva (2019b). No entanto, ao enfatizar o processo de empresarização da educação superior no Brasil, o referido texto não desenvolve teoricamente a referida perspectiva. E esse é justamente o foco da próxima seção.

\section{Foucault e as contribuições para a teoria da empresarização}

A segunda metade do século $\mathrm{XX}$ fora vigorosa no que tange ao surgimento de grandes pensadores das ciências sociais contemporâneas, sobretudo a partir da década de 1960. Dentre esses pensadores, destaca-se a figura de um cânone deste período, cujos escritos são mobilizados até os dias de hoje para a elaboração de estudos e reflexões nas mais diferentes áreas do conhecimento dada a magnitude e a profundidade de seus estudos, a saber: Michel Foucault.

As obras de Foucault são comumente divididas em três fases distintas, nas quais, em cada uma delas, o autor emprega maneiras de análises muito específicas, a saber: a arqueologia, a genealogia e a ética ${ }^{4}$ (DAVIDSON, 1986). $\mathrm{Na}$ fase arqueológica, o autor se dedicou a temas que envolvem discursos, conhecimento e verdade. Já na fase genealógica, o domínio de suas análises voltou-se para poder, disciplina e controle. E, por fim, em 
sua fase ética predominaram análises do sujeito e do relacionamento do eu consigo mesmo (LECLERCQ-VANDELANOITTE, 2011).

Diante da multiplicidade de temas e enfoques que fazem parte do universo das obras produzidas por Foucault, materializadas tanto em livros, como em cursos publicados, textos, artigos, conferências e entrevistas (BRAGA JÚNIOR, 2007), um leque de possibilidades se abre para a utilização de seu cabedal teórico a partir da realização de abordagens e reflexões que podem e são realizadas, não somente no campo da filosofia, como também da sociologia, da história, da educação, da administração, dentre outras.

Especificamente no âmbito dos estudos organizacionais, as obras de Foucault começaram a ser referenciadas com mais entusiasmo a partir dos anos de 1980, ganhando espaço, em especial, nos estudos críticos desse campo (PRESTES MOTTA; ALCADIPANI, 2004). Ao investigar mais a fundo os motivos que viabilizaram a introdução e a utilização das ideias de Foucault nos estudos organizacionais, Prestes Motta e Alcadipani (2004) apontam para a importância da ruptura na perspectiva funcionalista, até então dominante nessa área de estudo e que, consequentemente, oportunizou o avanço de vertentes teóricas de cunho mais crítico ${ }^{5}$.

Já no que tange aos estudos organizacionais brasileiros, destacam-se como seminais os trabalhos de Prestes Motta (1981) e de Segnini (1986), os quais foram, por sua vez, fundamentais para a articulação dos pressupostos de Foucault nesse contexto (SILVEIRA; TONELLI, 2004). Atualmente, é possível verificar a aplicação de diferentes conceitos fundamentais das obras de Foucault em uma gama de pesquisas, o que evidencia a atualidade de seus conceitos, bem como a abrangência de sua teoria para os estudos das organizações brasileiras.

Diante das considerações contextuais mencionadas, destaca-se que a presente pesquisa busca se inserir neste âmbito que visa a articular alguns dos conceitos de Michel Foucault junto aos estudos organizacionais, mais especificamente daqueles que abordam o tema da empresarização. Parece evidente destacar que o esforço teórico o qual se realiza aqui não irá cobrir a totalidade dos escritos do autor, mas sim buscar construir uma visão que se inspira em seu pensamento, resgatando alguns de seus conceitos.

$\mathrm{O}$ intuito de mobilizar as contribuições teóricas de algumas das obras de Michel Foucault está diretamente relacionado com o propósito de lançar um olhar complementar para se pensar o fenômeno da empresarização. Tal motivação parte da concepção que se tem acerca do processo de empresarização como um fenômeno total - social, econômico, político, cultural etc. -, o qual resulta e revela a centralidade e, mais especificamente, o poder que a empresa possui (RODRIGUES; SILVA, 2019a), ao ponto de ser considerada a força criadora e organizadora do mundo moderno (SOLÉ, 2004).
5 Dentre as vertentes de cunho crítico que impulsionaram a utilização do pensamento de Foucault nos estudos organizacionais, Silveira (2002) aponta para as análises organizacionais pós-modernas, as discussões no âmbito do "Labour Process Theory", além dos "Critical Management Studies". 
6 Episteme pode ser entendida como "[...] a ordem específica do saber, a configuração, a disposição que o saber assume em determinada época. E que lhe confere uma positividade como saber" (MACHADO, 2006, p. 133).

7 Sobre o poder, Foucault (1988, p. 89) descreve "[...] o poder não é uma instituição e nem uma estrutura, não é uma certa potência de que alguns sejam dotados: é o nome dado a uma situação estratégica complexa numa sociedade determinada".
De acordo com Solé (2008), assim como em outras épocas houve instituições que foram centrais e de grande influência na organização social, tal como a Igreja na Idade Média, foi com o desenvolvimento da sociedade moderna capitalista que a empresa passou a ganhar um lugar de referência, exercendo uma forte influência no tecido social. Tal influência torna-se evidente ao lembrar que são as empresas que produzem e que fornecem praticamente todos os bens e serviços existentes, impactando, diretamente, no atual modo de viver das pessoas, inclusive nos seus medos e nos seus sonhos.

Levando em consideração que os escritos de Solé $(2004,2008)$ e de Abraham (2006) apontam o fenômeno da empresarização como um fenômeno essencialmente moderno, inicia-se esta explanação considerando que é a partir do surgimento de uma episteme 6 específica, ou seja, de uma ordem, de um princípio de ordenação histórica dos saberes (MACHADO, 2006, p. 133), a saber, a episteme moderna, que se criaram condições para o estabelecimento de um conjunto de saber-poder singular, o qual tem como cerne o modelo empresarial. Entender a empresa como um conjunto de saber-poder significa afirmar que todo o poder existente em torno da ideia de empresa na modernidade está intimamente implicado com a existência de um campo de saber a ele relacionado, pois, conforme aponta Foucault (1987), não existe o estabelecimento de uma relação de poder sem que haja a constituição de um campo de saber. Isso porque todo saber implica a imposição e a constituição de relações de poder. Para o autor, tais relações funcionam como motor para a sua disseminação e que, por conseguinte, acabam pondo em circulação determinadas normas, crenças, práticas e cultura, as quais passam a ser difundidas por todo o social.

Ocorre que esse conjunto de saber-poder empresarial que expressa hoje a sua magnitude não emergiu ao acaso, pois é fruto de uma construção histórica que envolve um conjunto de possibilidades e de restrições as quais foram "[...] constituídas em construções discursivas e incorporadas em circunstâncias materiais e em recursos, que permitem certas ações e restringem outras" (LECLERCQ-VANDELANOITTE, 2011, p. 1254). Em outros termos, a construção desse saber-poder empresarial resulta de um amplo processo interativo de múltiplas relações, ações, determinações legais, conflitos e tensões entre as mais diversas vozes, dentre elas, a de governos, de entes privados, de organismos econômicos etc., que foram lentamente construídas, fortalecidas e disseminadas.

Embora Solé (2008) sinalize o processo de empresarização como um evento contingente, a concepção foucaultiana permite pensar o referido fenômeno de forma mais avançada. Para Foucault (2004), o $\operatorname{poder}^{7}$ (acerca de ideia de empresa) é historicamente construído não emana única e exclusivamente de si, assim como ele não se encontra centralizado em 
um único ponto, mas funciona e se exerce em rede. Ele se encontra em constante circulação e movimento, percorrendo os mais diferentes espaços sociais e aspectos da vida cotidiana, uma vez que o poder está nas relações e nas práticas, sejam elas de aceitação ou resistência (FOUCAULT, 2014).

A partir dessa assertiva, entende-se o poder da empresa não como centralizador e hierárquico, mas sim como algo relacional e dinâmico, que envolve diferentes forças, que se chocam e que se contrapõem dentro de uma mesma ordem, estruturando diferentes práticas que veiculam e põem em funcionamento tais relações de poder (MAIA, 1995). Desse modo, o exercício do poder é sempre uma estrutura de ações, ele "[...] incita, induz, seduz, torna mais fácil ou mais difícil; no extremo, restringe ou proíbe absolutamente; é, no entanto, sempre um modo de agir ou ser capaz de ações. Um conjunto de ações sobre outras ações" (FOUCAULT, 1982, p. 789). E, conforme indica Silva (2012), mesmo existindo aspectos repressivos, as relações de poder constituem-se em meios que asseguram a produção e a reprodução do saber-poder.

Como mencionado, a ideia de empresa, construída a partir de um processo histórico, bem como todo o seu poder, é mantida e sustentada por diferentes estratégias e correlações de forças que envolvem uma série de construções discursivas, além de diferentes estruturas e sistemas de controle, os quais são produzidos e disseminados pelas mais variadas fontes. Nesse contexto, os discursos assumem particular importância, tanto por representarem uma forma de exercício do poder (FOUCAULT, 1999a, 1999b) quanto por possibilitarem a criação de uma dimensão favorável ao estabelecimento de determinadas regras comportamentais, de atitudes e de diálogos socialmente aceitos e legitimados como padrões ideais de conduta a ser praticado pelos indivíduos (FARIA; MENEGHETTI, 2001). Foucault (2008a, p. 132) entende o discurso como "um conjunto de enunciados ${ }^{8}$, na medida em que se apoiam na mesma formação discursiva" Para o autor:

[...] ele [o discurso] não forma uma unidade retórica ou formal, indefinidamente repetível e cujo aparecimento ou utilização poderíamos assinalar (e explicar, se for o caso) na história; é constituído de um número limitado de enunciados para os quais podemos definir um conjunto de condições de existência. $\mathrm{O}$ discurso, assim entendido, não é uma forma ideal e intemporal que teria, além do mais, uma história; o problema não consiste em saber como e por que ele pôde emergir e tomar corpo num determinado ponto do tempo; é, de parte a parte, histórico - fragmento de história, unidade e descontinuidade na própria história, que coloca o problema de seus próprios limites, de seus cortes, de suas transformações, dos modos específicos de sua temporalidade, e não de seu surgimento abrupto em meio às cumplicidades do tempo. (FOUCAULT, 2008a, p. 132-133).
8 Entendido como a unidade elementar do discurso, "[...] é uma função de existência que pertence, exclusivamente, aos signos, e a partir da qual se pode decidir, em seguida, pela análise ou pela intuição, se eles 'fazem sentido' ou não, segundo que regra se sucedem ou se justapõem, de que são signos, e que espécie de ato se encontra realizado por sua formulação (oral ou escrita)" (FOUCAULT, 2008a, p. 98).

9 Segundo Foucault (2008a, p. 43) existe uma formação discursiva sempre que "[...] se puder descrever, entre um certo número de enunciados, semelhante sistema de dispersão, e no caso em que entre os objetos, os tipos de enunciação, os conceitos, as escolhas temáticas, se puder definir uma regularidade (uma ordem, correlações, posições e funcionamentos, transformações)". 
10 Por verdade, Foucault (2014, p. 13) entende como um "[...] conjunto das regras segundo as quais se distingue o verdadeiro do falso e se atribui ao verdadeiro efeitos específicos de poder".

11 De acordo com Solé (2008), no mundo moderno, a felicidade se constitui na satisfação das necessidades individuais. Logo, a forma como se satisfazem as necessidades (trabalho, consumo) na modernidade está intimamente relacionada com a empresa, aquela que estimula o individualismo, o egoísmo e o consumismo.
Os discursos possuem um suporte histórico e institucional que viabilizam e/ou inibem a sua reprodução, além de serem compreendidos como uma prática, pois seu sentido é produzido nas relações e nos enunciados em exercício (GIACOMONI; VARGAS, 2010). Esta prática, por sua vez, define-se como "[...] um conjunto de regras anônimas, históricas, sempre determinadas no tempo e no espaço, que definiram, em uma dada época e para uma determinada área [...], as condições de exercício da função enunciativa" (FOUCAULT, 2008a, p. 133). Foucault (1997, p. 12) destaca ainda que as práticas discursivas não são apenas uma forma de produzir discursos, pois elas “[...] ganham corpo em conjuntos técnicos, em instituições, em esquemas de comportamento, em tipos de transmissão e de difusão, em formas pedagógicas, que ao mesmo tempo as impõe e as mantêm".

Os discursos, portanto, não são produzidos aleatoriamente, mas seguem determinados interesses das instâncias e das relações de poder que lhe originam e acabam por se materializar nas práticas sociais de diferentes indivíduos, além de neles produzir efeitos (SILVA; MACHADO JUNIOR, 2014).

A ordem construída pela conjunção desses discursos, a partir da sua produção e reprodução, delineia “[...] a força e os efeitos práticos através dos quais um discurso se legitima e se efetiva dentro do corpo social” (GIMBO, 2016, p. 134), desenhando uma trama de significados que, por seu turno, reflete os pressupostos, os princípios e os valores que se encontram na sua base formadora.

Já no que concerne às estruturas e sistemas de controle, pode-se afirmar que seu conceito se aproxima daquilo que Foucault denomina de dispositivos disciplinares. Dispositivos que tendem a "[...] fazer com que as pessoas trabalhem de acordo com uma norma, um padrão que deve ser introjetado, ou seja, a pessoa deve agir de acordo com algo que lhe é imposto de fora" (SILVA; ALCADIPANI, 2004, p. 89).

Dessa forma, tais discursos, estruturas e sistemas de controle são arquitetados e disseminados a partir de um amplo processo histórico que envolve relações de força, disputas, jogos de interesses e tensões entre diferentes sujeitos, interessados e intimamente envolvidos nesse processo para que sejam legitimados socialmente, concorrendo para consolidar aquilo que será aceito e funcionará como verdadeiro (FOUCAULT, 2014). Ou seja, uma determinada política de verdade ${ }^{10}$, na qual as características e as maneiras de agir e de pensar que constituem a ideia empresa são naturalizadas e tomadas como referência, comumente associada aos ideais de desempenho, inovação, resultado, eficiência, progresso e, conforme destaca Solé (2008), como fonte de felicidade ${ }^{11}$. Assim, "[...] o que faz com que o poder se mantenha e que seja aceito é simplesmente que ele não pesa 
só como uma força que diz não, mas que de fato ele permeia, produz coisas, induz ao prazer, forma saber, produz discurso" (FOUCAULT, 2014, p. 45).

A supremacia desse conjunto de saber-poder específico implica não somente olhar com uma lente empresarial para todas as instituições e organizações, desprezando as suas peculiaridades inatas e distintas das empresariais, como também alude em algo muito mais complexo relacionado à disseminação de uma forma particular de como os indivíduos devem estar, devem ver e devem se posicionar no mundo em consonância com a ordem predominante (RODRIGUES; SILVA, 2014). Conforme destaca Foucault (2014), o indivíduo não é o outro do poder, alheio a ele, mas sim se constitui em um de seus principais efeitos. Logo, pode-se considerar que o indivíduo é uma produção do poder e do saber, já que não existe relação de poder sem a construção de um campo de saber, do mesmo modo que o saber constrói novas relações de poder (MACHADO, 2014).

Essa teia de relações de poder, de construções discursivas, de estruturas e sistemas de controle acaba por impactar na forma de ser e de agir dos indivíduos na sociedade. A tônica desse processo é a produção de subjetividades e de práticas individuais, as quais passam a alterar a percepção dos próprios indivíduos, bem como a maneira como se identificam. De tal modo, entende-se subjetividade como "[...] a maneira pela qual o sujeito faz a experiência de si mesmo em um jogo de verdade, no qual ele se relaciona consigo mesmo" (FOULCAULT, 2004, p. 236). Para o autor, a subjetividade é produto das relações de saber e de poder, bem como dos jogos de verdade situados em determinado momento histórico. Isso não significa afirmar que o sujeito é passivo perante essa trama social. Ele também possui capacidade para transformar sua subjetividade nas relações de si consigo mesmo. Corroborando este argumento, Foucault (1997, p. 109) argumenta que existem procedimentos, no decorrer da história, que foram “[...] pressupostos ou prescritos aos indivíduos para fixar sua identidade, mantê-la ou transformá-la em função de determinados fins, e isso graças a relações de domínio de si sobre si ou de conhecimento de si por si”.

Há, portanto, a construção de uma nova dimensão do homem, um novo princípio de conduta que orienta os indivíduos a se enxergarem e agirem enquanto empresas, emergindo o que Foucault (2008, p. 311) denomina de "empresário de si mesmo", sendo "[...] ele próprio seu capital, sendo para si mesmo seu produtor, sendo para si mesmo a fonte de [sua] renda”. Igualmente, o indivíduo é orientado a governar-se a si mesmo, em um constante processo de processo de formação de si (DARDOT; LAVAL, 2016). Dito de outro modo, um tipo particular de comportamento individual passa a ser potencialmente valorizado em decorrência da ampla disseminação da ideia de empresa, e que sintetiza, ao mesmo tempo, o “empresário de si” conforme descrito por Foucault (2008b): o empreendedor de si. Posto isso, 
A pura dimensão do empreendedorismo, a vigilância em busca da oportunidade comercial, é uma relação de si para si mesmo que se encontra na base da crítica à inferência. Somos todos empreendedores, ou melhor, todos aprendemos a ser empreendedores. Apenas pelo jogo de mercado nós nos educamos a nos governar como empreendedores. Isso significa também que, se o mercado é visto como um livre espaço para os empreendedores, todas as relações humanas podem ser afetadas por essa dimensão empresarial, constitutiva do humano. (DARDOT; LAVAL, 2016, p. 146).

Essa ênfase no "eu empreendedor", responsável de si mesmo, evidencia uma nova tendência no regime e na governança da educação e do bem-estar na qual os indivíduos devem procurar investir em pontos considerados cruciais no círculo da vida (PETERS, 2001) e, por conseguinte, não devem mais se enxergar como trabalhadores, mas sim como empresas que procuram vender um serviço no mercado (DARDOT; LAVAL, 2016).

Desse modo, injunge-se o sujeito a conformar-se intimamente, por um trabalho interior constante, à seguinte imagem: ele deve cuidar constantemente para ser o mais eficaz possível, mostrarse inteiramente envolvido no trabalho, aperfeiçoar-se por uma aprendizagem contínua, aceitar a grande flexibilidade exigida pelas mudanças incessantes impostas pelo mercado. Especialista em si mesmo, empregador de si mesmo, inventor de si mesmo, empreendedor de si mesmo: a racionalidade neoliberal impele o eu a agir sobre si mesmo para fortalecer-se, assim, sobreviver na competição. (DARDOT; LAVAL, 2016, p. 330-331).

Infere-se, pois, que a empresa, além de ser o modelo ideal a ser imitado por outras organizações e instituições, também funciona como uma referência que parece nortear o ethos do indivíduo moderno, pois acaba por influenciar na delimitação de comportamentos, além de sinalizar as atitudes desejadas, valorizadas e pretensamente virtuosas. Conforme apontam Dardot e Laval (2016, p. 328):

Do sujeito ao Estado, passando pela empresa, um mesmo discurso permite articular uma definição do homem pela maneira como ele quer ser "bem-sucedido", assim como pelo modo como deve ser "guiado", "estimulado", "formado", "empoderado" (empowered) para cumprir seus objetivos.

A construção dessa nova subjetividade molda o sujeito, para que ele se comporte como uma "[...] entidade em competição e que, por isso, deve maximizar seus resultados, expondo-se a riscos e assumindo inteira responsabilidade por eventuais fracassos"(DARDOT; LAVAL, 2016, p. 328).

Ante ao que foi até aqui exposto, no que concerne à forma como se compreende, neste trabalho, a ideia de empresa, bem como o fenômeno da 
empresarização e de seus desdobramentos, apresenta-se a Figura 1, a seguir ilustrada, como um esforço de síntese dos pressupostos desenvolvidos até o presente momento.

Figura 1 - Síntese teórica

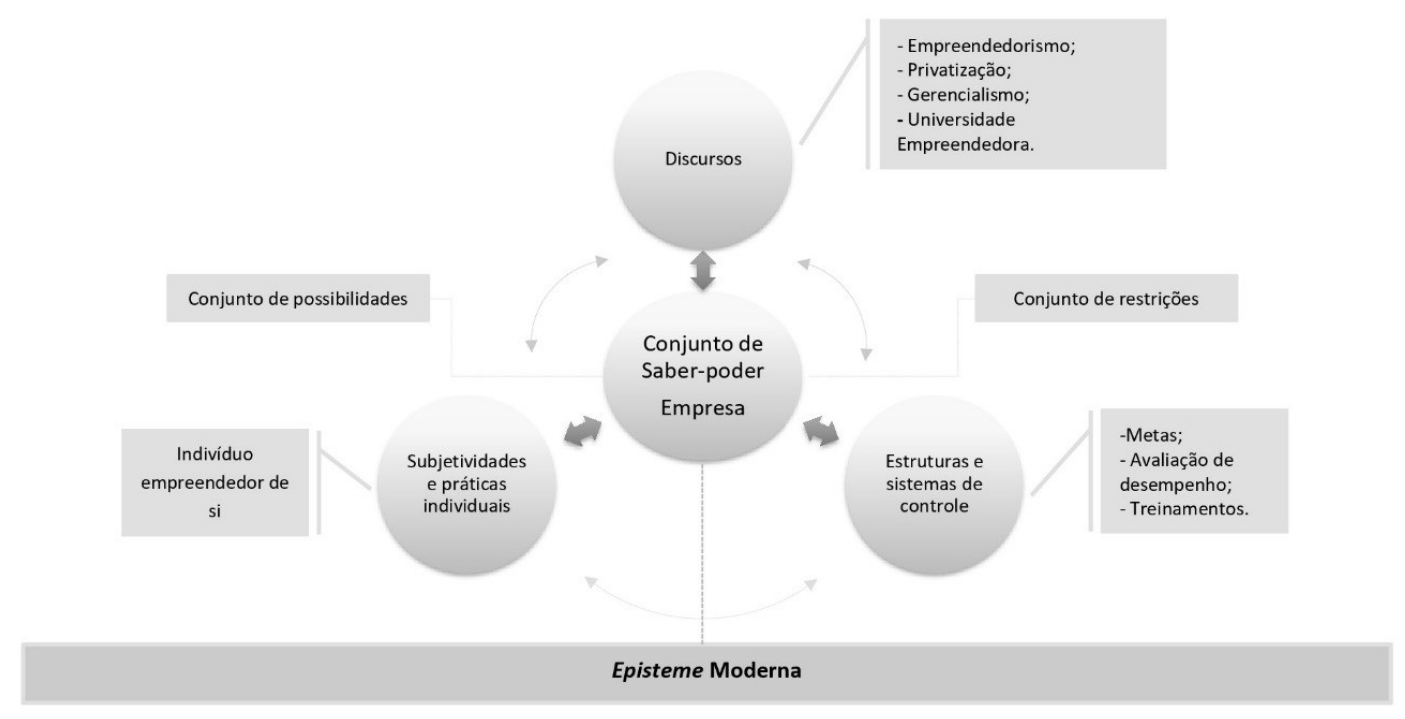

Fonte: Adaptada de Leclercq-Vandelannoitte (2011).

Percebe-se, então, que a episteme moderna capitalista faz emergir um conjunto de saber-poder específico, o qual tem em seu cerne o modelo empresarial. Esse conjunto de saber-poder, construído ao longo do tempo por uma gama de diferentes relações que envolvem conjuntos de possibilidades e restrições incrustadas em diferentes construções discursivas, foi histórica e racionalmente justificado e funciona como uma espécie de base comum, a qual influencia na forma como os indivíduos percebem e se posicionam no mundo (criação de novas subjetividades e novas práticas individuais).

O processo de sustentação e manutenção desse conjunto de saberpoder empresarial existe e ocorre pela produção e disseminação dos mais variados discursos, bem como de diferentes estruturas e sistemas de controle que estão intimamente ligados a este conjunto de saber-poder específico, seja como força de aceitação ou de negação. A produção e a disseminação desses discursos e dessas estruturas e sistemas de controle ocorrem por meio de disputas, relações de força, de poder e de tensões que envolvem uma série de ações, concepções, argumentações, textos e falas que, lentamente, vão se fortalecendo e fazendo com que essa se torne a forma comum e legitimada de enxergar o mundo.

A grande vantagem do estabelecimento dessa racionalidade empresarial, sutilmente disseminada por todo tecido social, reside no fato de que ela é capaz de unir as diversas relações de poder existentes na trama 
de um mesmo conjunto de construções discursivas, as quais têm em seu cerne o saber-poder empresarial e que, por sua vez, sustentam a noção de que a empresa se constitui na forma ótima de organizar os mais diferentes domínios do social (DARDOT; LAVAL, 2016).

\section{Considerações finais}

O esforço empreendido no presente trabalho foi direcionado à apresentação e à discussão das pesquisas realizadas sobre o processo de empresarização no Brasil, notadamente, aquelas desenvolvidas na área de estudos organizacionais, com o intuito de traçar um panorama e apontar outras possibilidades para se (re)pensar o referido processo. Diante do cenário composto pelas pesquisas que utilizam como pano de fundo teórico o processo de empresarização, pode-se destacar que grande parte delas toma como referente principal os escritos desenvolvidos por Solé e por Abraham para discutir a centralidade da empresa.

É possível perceber o esforço por parte de alguns autores para ampliar e/ou desenvolver a perspectiva teórica ora colocada em evidência, sobretudo na tentativa de associar outros autores àqueles anteriormente mencionados. Corroborando com o que fora dito, podem ser citados os trabalhos de Tometich (2019) e Tometich e Silva (2018) que buscaram realizar uma associação com o marxismo, o trabalho de Duquia (2018) que mobiliza autores da administração pública, o trabalho de Borges, Barcelos e Rodrigues (2018) que articula autores institucionalistas, além do trabalho de Barcelos e Rodrigues (2017) que buscou vincular autores do âmbito das políticas públicas e, ainda, aquele escrito por Costa (2017) que inclui autores brasileiros na discussão.

Com base no que foi exposto, ressalta-se que poucas são as pesquisas que efetivamente propõem uma nova forma de pensar o processo de empresarização ou de superar as limitações teóricas presentes nas propostas de Solé $(2004$, 2008) e Abraham (2006), sobretudo no que tange à visão dos autores com relação à empresa vista como uma organização (SOLÉ, 2004, 2008) e à empresa vista como uma instituição (ABRAHAM, 2006), visto que a primeira perde ao dar pouca potência ao fenômeno da empresarização, enquanto a segunda parece suprimir as relações de poder ao adotar uma perspectiva essencialmente funcionalista.

Em uma primeira tentativa de desenvolver uma perspectiva que pudesse superar algumas das lacunas elencadas, Rodrigues e Silva (2019b) desenvolveram uma visão inicial que articula os escritos de Foucault aos estudos sobre empresarização. Tendo isso em vista, e tomando como ponto de partida os trabalhos de Solé $(2004,2008)$ e Abraham (2006) acerca do processo de empresarização, a proposta deste artigo está relacionada com o intuito de ir em busca do desenvolvimento de um novo olhar para este 
fenômeno, a partir de uma perspectiva, até então, pouco explorada na área dos estudos organizacionais, a saber: a perspectiva foucaultiana.

Para Foucault (2008), a partir desenvolvimento do neoliberalismo, sobretudo o neoliberalismo Americano, o que se observa é uma generalização da forma de empresa pelo interior do tecido social, como se este fosse um modelo universalmente generalizável. Segundo o autor, é nesse contexto que uma lente econômica passa a ser utilizada para olhar fenômenos não mercantis, fenômenos que não pertencem, necessariamente, ao âmbito econômico. Tal fato acaba por culminar, no limite, com a emergência daquilo que Foucault (2008) denomina de um indivíduo "empresário de si mesmo", sujeito altamente valorizado em decorrência da generalização do modelo da empresa.

Ao inserir uma perspectiva foucaultiana nos estudos acerca do processo de empresarização, busca-se evidenciar o alcance que o fenômeno possui por meio da construção de uma visão que privilegia as relações de poder, além de enfatizar que a empresa, aqui entendida como um conjunto de saber-poder, não emerge ao acaso, mas advém justamente das múltiplas relações, ações, determinações legais, entre outros aspectos, que vão, lentamente, fortalecendo e fazendo com que essa se torne a forma comum de enxergar o mundo. Assim, ao se lançar um olhar complementar a partir dos escritos de Michel Foucault, entende-se o processo de empresarização como um processo que ocorre de forma sutil, mas que se torna, ao mesmo tempo, um processo de grande potencialidade quanto ao seu alcance. $\mathrm{O}$ olhar foucaultiano pode permitir a reflexão sobre o papel que os indivíduos e as instituições e organizações possuem no que se refere a essa generalização da ideia de empresa pelo tecido social. Uma generalização que ocorre por intermédio de sua reprodução, como já anteriormente mencionado, de forma sútil e fluida, exatamente pelo fato de que o poder que a empresa materializa na modernidade não está localizado em um único ponto, mas encontra-se em constante circulação, sendo incorporado e reproduzido nos mais variados discursos, muitas vezes de forma acrítica e ahistórica.

Em síntese, acredita-se que, ao lançar um olhar de inspiração foucaultiana para os estudos sobre o processo de empresarização, pode-se contribuir epistemologicamente, metodologicamente e teoricamente com essa teoria. No que tange ao aspecto epistemológico, o fato de Foucault possuir uma obra que se assenta em uma perspectiva arqueológica e genealógica contribui para evitar alguns conflitos epistemológicos presentes nos escritos de Solé e Abraham. Solé, por exemplo, apresenta esse conflito epistemológico ao partir de uma noção idealista de empresa e, posteriormente, para fundamentar as suas ideias, às associa a alguns autores materialistas. Além disso, a obra de Foucault também ajuda a superar a visão funcionalista presente nos escritos de Abraham, quando o autor 
afirma que se apoia em Durkheim para defender a ideia de empresa como uma instituição.

Ademais, a partir da utilização de Foucault como referencial, temse a possibilidade de operacionalizar a discussão acerca do processo de empresarização. Uma vez que, ao mencionar em seus escritos os discursos, as tecnologias, as relações de poder, os sistemas de controle, entre outros, o pensador acaba por apontar caminhos para se pensar metodologicamente esse processo. Dito isso, o processo de empresarização, a partir de Foucault, pode ser analisado tanto nos termos de sua constituição, pois a teoria foucaultiana fornece um instrumento que permite realizar uma arqueologia da construção do saber-empresa, além de possibilitar, também, identificar e compreender as implicações resultantes desse fenômeno, por exemplo, através da noção de indivíduo empreendedor de si, reflexo desse processo. Por fim, além das contribuições e dos desdobramentos teóricos possíveis, os quais foram mencionadas anteriormente, o uso das obras de Foucault permite, também, deixar mais evidente a dimensão do poder quando se discute sobre o processo de empresarização, principalmente quando o autor ressalta como o poder da empresa constitui, ao mesmo tempo, em que funciona como um modo de governo de si e dos outros.

Ao chegar ao que se considera o final deste trabalho, abre-se um leque de possibilidades para a realização de novas e futuras investigações a partir do que fora aqui proposto. Dito isso, vislumbra-se a possibilidade de novos caminhos serem traçados mediante a realização de pesquisas que utilizem a lente teórica referente ao processo de empresarização a partir das contribuições desenvolvidas neste artigo junto às mais diferentes organizações existentes, sejam elas mantidas ou não pelo Estado, tal como organizações culturais, esportivas, educacionais, científicas, ambientais, entre outras, em seus mais diferentes níveis de análise (organizacional, individual etc.) que possibilitem, ademais, vislumbrar como tais organizações têm contribuído para esse processo de generalização da forma de empresa. A partir do que fora aqui proposto, ressalta-se que futuros estudos podem ser realizados tendo como objeto de análise os diferentes discursos que circulam nas organizações. Discursos estes que mantêm ao mesmo tempo que fortalecem o processo de empresarização, tal como o próprio discurso do empreendedorismo, da inovação, da privatização, do ranqueamento, do produtivismo etc.

Além dos discursos, sugere-se, ainda, a construção de trabalhos que tenham como foco o estudo de diferentes estruturas e sistemas de controle, tal como o estabelecimento de metas, de treinamentos, de ferramentas de avaliação de desempenho, assim como da própria questão da produção de novas e diferentes subjetividades e práticas individuais suscitadas pela ampla disseminação do modelo empresarial, inclusive como norma de 
comportamento para os indivíduos, os quais devem pensar e agir como “indivíduos-empresas”. Cabe mencionar, também, a ampliação dos estudos no que tange à própria constituição de um regime de verdade, o qual resulta dessa generalização da ideia de empresa para os mais variados âmbitos da vida social e que toma como inquestionável e naturalizado o modelo empresarial.

Em linhas gerais, acredita-se ser importante salientar que a motivação central na construção deste texto está centrada, acima de tudo, em contribuir com o tema da empresarização e em buscar fornecer um material complementar para que se possa pensar, refletir e analisar sobre esse processo que avança sobre tudo e sobre todos a cada dia mais.

\section{Referências}

ABRAHAM, Y.-M. L'entreprise est-elle nécessaire? In: DUPUIS, J.-P. (Org.). Sociologie de l'entreprise. Montréal: Gaëtan Morin Editeur, 2006. p. 323-374.

ARAÚJO, A. Z. Impacto a política pública de agricultura familiar nas relações dos agricultores: uma análise fundamentada na teoria da empresarização. Orientadora: Rosimeri Carvalho da Silva ?. 2014.119 f. Dissertação (Mestrado em Administração) - Programa de Pós-Graduação em Administração, Universidade Federal do Rio Grande do Sul, Porto Alegre, 2014.

ARAÚJO, A. Z.; SILVA, R. C. da. A Agricultura Familiar e a expansão das Relações Sociais inerentes à Empresa. Estudos Sociedade e Agricultura, Rio de Janeiro, v. 24, n. 1, p. 85-112, 2016.

BADIA, O. de C. O posicionamento das empresas de educação na construção do Plano Nacional de Educação 2014-2024: uma análise a partir da teoria da empresarização. Orientadora: Rosimeri Carvalho da Silva.2017.125 f. Dissertação (Mestrado em Administração) - Programa de Pós-Graduação em Administração, Universidade Federal do Rio Grande do Sul, Porto Alegre, 2017.

BORGES, J. C. P.; BARCELOS, M.; RODRIGUES, M. S. Empresarização da saúde pública: o caso da EBSERH. Revista Pensamento Contemporâneo em Administração, v. 12, n. 4, p. 75-90, out./dez. 2018.

BORGES, J. C. P.; RODRIGUES, M. O Estado e a generalização da forma empresa: uma análise da percepção de agentes públicos acerca do papel da Secult em Pelotas/RS. Revista Sinergia, v. 21, n. 2, p. 81-94, jul./dez. 2017.

BRAGA JÚNIOR, M. A legitimidade e os corpos políticos. Barueri: Minha Editora, 2007.

CONSIDINE, M. Enterprising States: The Public Management of Welfare-toWork. Cambridge: Cambridge University Press, 2001.

COSTA, C. E. S. da. Processo de Empresarização nos clubes de futebol e as conseqüências sobre o controle organizacional. Orientadora: Rosimeri Carvalho da Silva. 2005. 208 f. Dissertação (Mestrado em Administração) - Programa de Pós-Graduação em Administração, Universidade Federal de Santa Catarina, Florianópolis, 2005. 
COSTA, C. E. S. da; SILVA, R. C. da. Empresarização e controle organizacional: um estudo nos clubes de futebol em Santa Catarina. Cadernos EBAPE.BR, Rio de Janeiro, v. 4, n. 4, p. 1-16, 2006.

COSTA, C. S. N. A Empresarização do Espaço em Cidades Locais: um estudo no município de São José do Norte. Orientadora: Rosimeri Carvalho da Silva. 2017. 100 f. Tese (Doutorado em Administração) - Programa de Pós-Graduação em Administração, Universidade Federal do Rio Grande do Sul, Porto Alegre, 2017.

DARDOT, P.; LAVAL, C. A nova razão do mundo: ensaio sobre a sociedade neoliberal. São Paulo: Boitempo, 2016.

DAVIDSON, A.I.Archaeology, genealogy, ethics. In: HOY,D. C.(Ed.). Foucault: A critical reader. Oxford: Blackwell, 1986. p. 221-233.

DUQUIA, A. A. O processo de empresarização da pós-graduação: uma análise dos tipos de governança presentes na Universidade Federal de Pelotas. Orientador: Marcio Silva Rodrigues. 2018. 163 f. Dissertação (Mestrado em Desenvolvimento Territorial e Sistemas Agroindustriais) - Programa de Pós-Graduação em Desenvolvimento Territorial e Sistemas Agroindustriais, Universidade Federal de Pelotas, Pelotas, 2018.

DURIEUX, A. O processo de empresarização do voleibol catarinense. Orientadora: Eloise Helena Livramento Dellagnelo. 2005. 146 f. Dissertação (Mestrado em Administração) - Programa de Pós-Graduação em Administração, Universidade Federal de Santa Catarina, Florianópolis, 2005.

FARIA, J. H. de; MENEGHETTI, F. K. Discursos organizacionais. In: EnANPAD, 25., 2001, Campinas. Anais... Campinas, SP: ANPAD, 2001.p. 1-16.

FOUCAULT, M. The Subject and power. Critical Inquiry, Chicago, v. 8, n. 4, p. 777-795, 1982. Disponível em: http://www.unisa.edu.au/Global/EASS/HRI/ foucault_-_the_subject_and_power.pdf. Acesso em: 9 jan. 2018.

FOUCAULT, M. Vigiar e punir: nascimento da prisão. Petrópolis: Vozes, 1987.

FOUCAULT, M. História da Sexualidade. Vol. 1: A vontade de saber. Rio de Janeiro: Edições Graal, 1988.

FOUCAULT, M. Resumo dos cursos do Collège de France (1970- 1982). Rio de Janeiro: J. Zahar, 1997.

FOUCAULT, M. A ordem do discurso. São Paulo: Edições Loyola, 1999a.

FOUCAULT, M. La ética del cuidado de sí como práctica de la libertad. In: FOUCAULT, M. Estética, ética e hermenêutica: obras esenciales. Barcelona: Paidós, 1999b. v. 3.p. 393-415.

FOUCAULT, M. Ética, sexualidade e política. In: MOTTA, M. B. (Org.).Ética, sexualidade e política. Rio de Janeiro: Forense Universitária, 2006. p. 234-239.

FOUCAULT, M. A Arqueologia do Saber. Rio de Janeiro: Forense Universitária, 2008a.

FOUCAULT, M.. O nascimento da biopolítica. São Paulo: Martins Fontes, $2008 \mathrm{~b}$

FOUCAULT, M. Microfísica do Poder. 28. ed. Rio de Janeiro: Paz e Terra, 2014. 
GIACOMONI, M. P.; VARGAS, A. Z. Foucault, a arqueologia do saber e a formação discursiva. Veredas - Revista de Estudos Linguísticos, Juiz de Fora, v. 14, n. 2, p. 119-129, 2010.

GIMBO, F. S. Da ordem do discurso ao discurso da ordem: da relação entre saber e poder em Foucault. Sapere Aude, v. 7, n. 12, p. 132-154, jan./jun. 2016.

GOMES, D. de. O último Focault e o retorno transversal aos gregos. Archai Journal, n. 9, p. 37-44, jul./dez. 2012.

GONÇALVES,J.C.de S.; SERRA,A.R. C.; COSTA, C.E. S.A empresarização do sagrado: um estudo sobre a estruturação de igrejas protestantes brasileiras. Revista Eletrônica de Ciência Administrativa, v. 6, n. 2, p. 1-14, 2007.

HARVEY, D. Breve historia del neoliberalismo. Madri: Ediciones Akal, 2007.

LECLERCQ-VANDELANOITTE,A.Organizations as discursive constructions: a foucauldian approach. Organization Studies - SAGE Publications,v. 32, n. 9, p. 1247-1271, 2011.

MACHADO, R. Foucault, a ciência e o saber. Rio de Janeiro: Jorge Zahar, 2006.

MACHADO, R. Introdução: por uma genealogia do poder. In: FOUCAULT, M. Microfísica do Poder. 28. ed. Rio de Janeiro: Paz e Terra, 2014. p.7-34.

MAIA, A. C. Sobre a analítica do poder de Foucault. Tempo Social, São Paulo, USP, v. 7, n. 1-2, p. 83-103, 1995.

NEVES, L. M. W. (Org.). O empresariamento da educação: novos contornos do ensino superior no Brasil dos anos de 1990. São Paulo: Xamã, 2002.

PEREIRA, M. E. M.; GIOIA, S. C. Séculos XVIII e XIX: revolução na economia e na política. In: ANDERY et al. (Org.). Para compreender a Ciência: uma perspectiva histórica. São Paulo: EDUC, 2004. p. 257-294.

PETERS, M. Education, enterprise culture and the entrepreneurial self: a foucauldian perspective. Journal of education alenquiry, v. 2, n. 2, p.58-71, 2001. Disponível em: https://www.ojs.unisa.edu.au/index.php/EDEQ/article/view/558. Acesso em: 25 fev. 2018.

PRESTES MOTTA, F. C. O Poder Disciplinar nas Organizações Formais. RAE, v. 21, n. 4, p. 33-41, 1981.

PRESTES MOTTA, F. C.; ALCADIPANI, R. O pensamento de Michel Foucault na teoria das organizações. Revista de Administração, São Paulo, v. 39, n. 2, p. 117-128, abr./maio/jun. 2004.

RODRIGUES, M.da S.Mercadores de emoção: um estudo sobre a empresarização dos clubes de futebol brasileiros. Orientadora: Rosimeri Carvalho da Silva. 2006. 197 f. Dissertação (Mestrado em Administração) - Programa de Pós-Graduação em Administração, Universidade Federal de Santa Catarina, Florianópolis, 2006.

RODRIGUES, M. da S. O novo ministério da verdade: o discurso de VEJA sobre o campo do Ensino Superior e a consolidação da empresa no Brasil. Orientadora: Rosimeri Carvalho da Silva. 2013. 410 f. Tese (Doutorado em Administração) Programa de Pós-Graduação em Administração, Universidade Federal de Santa Catarina, Florianópolis, 2013. 
RODRIGUES, M. S.; SILVA, R. C. da. Empresarização no Figueirense Futebol Club e no Sport Club Internacional. Gestão. Org, Recife, v. 4, n. 3, p. 38-54, 2006 a.

RODRIGUES, M. S.; SILVA, R. C. da. Clientes ou torcedores: a empresarização do futebol no Brasil. Revista Alcance, Biguaçu, v. 13, n. 2, p. 167-184, 2006 b.

RODRIGUES, M. S.; SILVA, R. C. da. Estrutura Empresarial nos Clubes de Futebol. Organizações \& Sociedade, Salvador, v. 16, n. 17-37, p. 20-40, 2009.

RODRIGUES, M. S.; SILVA, R. C. da.. Empresarização e modernidade: a ideia de empresa no centro do mundo. Revista Brasileira de Estudos Organizacionais, v. 6, n. 1, p. 40-76, abr. 2019a. Disponível em: https://rbeo.emnuvens.com.br/rbeo/ article/view/147/pdf. Acesso em: 16 jun. 2019.

RODRIGUES, M. S.; SILVA, R.C. da. Nova república, novas práticas: uma análise do processo de empresarização do ensino superior no Brasil (1990 - 2010). Revisa de Estudos Organizacionais e Sociedade (Farol), v. 6, n. 15, p. 176-218, 2019 b. Disponível em: https://revistas.face.ufmg.br/index.php/farol/article/view/4855. Acesso em: 25 jun. 2019.

RODRIGUES, M. S.; SILVA, R. C. da New republic, new practices: a narrative of enterprisation of Higher Education in Brazil. In: LAEMOS Conference Latin American European Meeting on Organizational Studies, 5., 2014, Havana. Anais... Havana: LAEMOS Conference, 2014.

RODRIGUES, M. S.; SILVA, R. C. da.; DELlaGNELO, E. H. L. O Processo de Empresarização em Organizações Culturais Brasileiras. Revista Pensamento Contemporâneo em Administração, Rio de Janeiro, v. 8, n. 1, p. 66-85, jan./mar. 2014.

SEGNINI, L. Bradesco: A liturgia do poder. São Paulo: EDUC, 1986.

SERRA, A.R. C. A empresarização do sagrado: um estudo sobre a estruturação de igrejas dos protestantismos brasileiros. Orientadora: Rosimeri Carvalho da Silva. 2005. 195f. Dissertação (Mestrado em Administração) Programa de Pós-Graduação em Administração, Universidade Federal de Santa Catarina, Florianópolis, 2005.

SILVA, G. F. da; MACHADO JUNIOR, S. da S. O discurso em Michel Foucault. História em Reflexão, v. 8, n. 16, p. 1-14, jul./dez. 2014.

SILVA, R. C. da; ALCADIPANI, R. As transformações do controle na Siderúrgica Riograndense: uma análise Foucaultiana. O\&S, v. 11, n. 9, p. 81-96, jan./abr. 2004.

SILVA,T. C. da. Biopolítica: As relações saber-poder e governo no pensamento de Michel Foucault. Orientador: Ivo Silva Junior. 2012.126 f. Dissertação (Mestrado em Filosofia - Escola de Filosofia, Letras e Ciências Humanas, Universidade Federal de São Paulo, Guarulhos, 2012.

SILVEIRA, R. A. da. Michel Foucault, Poder e Análise das Organizações. Orientador: Fernando Claudio Prestes Motta. 2002. 197 f. Dissertação (Mestrado em administração) - Escola de Administração de Empresas de São Paulo, Fundação Getúlio Vargas, São Paulo, 2002.

ILVEIRA, R. A. da; TONELLI, M. J. Governamentalidade e a teoria das organizações. In: ENANPAD, 28., 2004. Curitiba. Anais... Curitiba: ANPAD, 2004. p. 1-15. 
SOLÉ, A. ¿Qué es una empresa? Construcción de un ideal tipo transdisciplinario. Paris: Working Paper, 2004.

SOLÉ, A. L'enterprisation du monde. In: CHAIZE, J.; TORRES, F. Repenserl'entreprise: Saisir ce qui commence, vingt regards sur une idée neuve. Paris: Le Cherche Midi, 2008. p. 27-54.

TAVARES, L. F. Empresa, Mercado e Cultura: o processo de empresarização no Grupo Tholl. Orientador: Marcio Silva Rodrigues. 2011. 88 f. Trabalho de Conclusão de Curso (Graduação em Administração) - Universidade Federal de Pelotas, Pelotas, 2011.

TOMETICH, P. O empreendedorismo como uma relação assalariada: um estudo sobre um traço da empresarização. Orientadora: Rosimeri de Fátima Carvalho da Silva. 2019. 196 f. Tese. (Doutorado em Administração) - Programa de Pós-Graduação em Administração, Universidade Federal do Rio Grande do Sul, Porto Alegre, 2019.

TOMETICH, P.; SILVA, R. C. da. O processo de empresarização e as mudanças nas relações de assalariamento e exploração. Revista Pensamento Contemporâneo em Administração, v. 12, n. 2, p. 71-87, abr./jun. 2018.

VAINER, C. B. Pátria, empresa e mercadoria: Notas sobre a estratégia discursivas do Planejamento Estratégico Urbano. In: ARANTES, O.; VAINER, L. C.; MARICATO, E. A cidade do pensamento único: desmanchando consensos. Petrópolis: Editora Vozes, 2000. p. 75-104.

VARGAS, L. M. Do monopólio à espetacularização da cultura: uma análise do processo de empresarização dos Centros de Tradições Gaúchas. Orientador: Marcio Silva Rodrigues. 2018.192 f. Dissertação (Mestrado em Desenvolvimento Territorial e Sistemas Agroindustriais) - Programa de Pós-Graduação em Desenvolvimento Territorial e Sistemas Agroindustriais, Universidade Federal de Pelotas, Pelotas, 2018.

Submetido: 05/08/2019

Aceito: 01/09/2019 


\title{
RETHINKING THE PROCESS OF ENTERPRISING:THE INSERTION OF A LOOK OF FOUCAULTIAN INSPIRATION
}

\begin{abstract}
The Modern societies have been experiencing a process characterized by a broad and strong influence of the enterprise model on humans, their organizations and institutions, known as the world's enterprising process. The central point of this paper is to explore the world's enterprising process by conducting a discussion that addresses the studies already done on this topic in the Brazilian scope of organizational studies. Therefore, we intend to propose a new way to rethink the writings on this phenomenon in the light of a Foucaultian perspective. From this new perspective, based on Michel Foucault's work, we seek to point out to the studies on the enterprising process, new theoretical, methodological and epistemological contributions, which may help to understand and deepen this phenomenon, highlighting the operability and potentiality from Foucaultian reading to research that encompasses this theme.
\end{abstract}

Keywords: Enterprising. Enterprise. Michel Foucault.

\section{REPENSANDO EL PROCESO DE EMPRESARIZACIÓN: LA INSERCIÓN DE UNA MIRADA DE INSPIRACIÓN FOUCAULTIANA}

\begin{abstract}
Resumen
Las sociedades modernas han experimentado un proceso caracterizado por una influencia amplia y fuerte del modelo empresarial sobre los humanos, sus organizaciones e instituciones, conocido como el proceso de empresarización del mundo. Dicho esto, el punto central de este documento es explorar el proceso de empresarización del mundo llevando a cabo una discusión que aborde los estudios ya realizados sobre este tema en el ámbito brasileño de los estudios organizacionales. Además, tenemos la intención de proponer una nueva forma de repensar los escritos sobre este fenómeno a la luz de una perspectiva foucaultiana. Desde esta nueva perspectiva, basada en el trabajo de Michel Foucault, buscamos señalar a los estudios sobre el proceso de empresarización nuevas contribuciones teóricas, metodológicas y epistemológicas, que pueden ayudar a comprender y profundizar este fenómeno, destacando la operatividad y potencialidad de la lectura foucaultiana a las investigaciones que abarcan este tema.
\end{abstract}

Palabras clave: Empresarización. Empresa. Michel Foucault. 